\title{
Microfadeometry of Miss Breme Jones Watercolor with Iron-gall Ink Inscriptions
}

\author{
Pamela Young ${ }^{1}$, Patricia Silence ${ }^{1}$, and Thomas Lam ${ }^{2}$ \\ ${ }^{1}$ Colonial Williamsburg Foundation, Williamsburg, VA, USA \\ ${ }^{2}$ Museum Conservation Institute, Smithsonian Institution, Suitland, MD, USA
}

The work on paper, Miss Breme Jones, is in the collections of the Colonial Williamsburg Foundation, Williamsburg, VA. The image is composed of thinly applied watercolor paint with iron-gall ink inscriptions. Miss Breme Jones, dated 1785-1787, is a rare portrait of an African-American woman. The painting was requested for a 10-month loan by the Smithsonian National Portrait Gallery for inclusion in the current exhibit The Sweat of Their Face: Portraying American Workers. Artifacts in the CW collections are given a light exposure allowance which is a finite number of hours before irreparable damage is done to the organic material components. Damage is recognizable as fading or a color shift in colorants and darkening of cellulosic materials. In collaboration with the Smithsonian Museum Conservation Institute, microfadeometry was performed to assess whether an expensive light mitigation system would be required.

Microfadeometry is a spectroscopy technique that measures the visible reflectance from wavelengths of 400 to $700 \mathrm{~nm}$ of a focused test analytical spot of $3 \mathrm{~mm}$ and calculates 1976 CIELAB color space values as specified by the International Commission on Illumination approximately every few seconds that allows for the assessment of fading the materials. This technique is considered a non-destructive because of the small size of the test spot (analytical spot is $3 \mathrm{~mm}$ and potential degradation spot is $0.2-0.4 \mathrm{~mm}$ ). Fading measurements were performed with the Oriel 80190 Fading Test System (Newport Oriel Corporation) that is equipped with an IR filtered Xe lamp light source and the visible reflected light from the spot is then collected by a fiber optic taken to the spectrometer unit. Measurements were carried out till 300 seconds is reached. Color change is measured by $\Delta \mathrm{E}^{*}$, where $\Delta E^{*}=\sqrt{\left(L_{0}^{*}-L_{t}^{*}\right)^{2}+\left(a_{0}^{*}-a_{t}^{*}\right)^{2}+\left(b_{0}^{*}-b_{t}^{*}\right)^{2}}$. In this equation, the original $\mathrm{L}^{*}, \mathrm{a}^{*}, \mathrm{~b}^{*}$ values at time zero are $L_{0}^{*}, a_{0}^{*}, b_{0}^{*}$ and $L_{t}^{*}, a_{t}^{*}, b_{t}^{*}$ are values at a given time elapsed since time zero. A $\Delta \mathrm{E}^{*} \approx 2.3$ units has been reported in the literature to be the just noticeable difference (JND), and values less than 2.3 would not be noticeable by the naked eye [1]. The assessment of the relative kinetics of fading was performed by comparison of the material with different grades of blue wool standards (Light Fastness Standards ISO/BS SDL Atlas USA, Rock Hill). The JND for blue wool standards (blue wool 1(BW1), blue wool 2 (BW2), and blue wool 3 (BW3)) have been established and are classified into ASTM categories for lightfastness [2].

Fig. 1. shows the selected areas for microfadeometry analysis on the watercolor Miss Breme Jones. Fig. 2 shows the microfading data average for the red and average for the arm regions to most stable within this watercolor, which faded at a slower rate than a BW3. Fig. 3 shows the microfading data of the analytical spot on the hair and paper, which faded at a faster rate than a BW3 but slower rate than a BW2. Fig. 4 shows the microfading data average for the blue region and the ink on the "R", which faded at a slightly rate faster than a BW2 but slower rate than a BW1. It was concluded that the most sensitive elements of the painting are the blue colorant and the iron-gall ink, which behaved comparably to a BW2. Through iron-gall ink has been shown to have reversible fading behavior in microfadeometry, leaning towards the safer recommendations especially for the blue colorant, a loan was approved with the stipulation that light levels in the museum gallery must be equal to or lesser than 137,000 lux hours for the loan duration, which could be achieved with the existing gallery lighting system $[2,3]$. 


\section{References:}

[1] M. Mahy et al., Color Research \& Application 19 (1994), 105-121.

[2] http://www.drb-mattech.co.uk/uv\%20blue\%20wool.html

[3] B. Ford and I. Batterham, The $8^{\text {th }}$ AICCM Book, Paper and Photographic Materials Symposium Sydney (2014), 14-20.

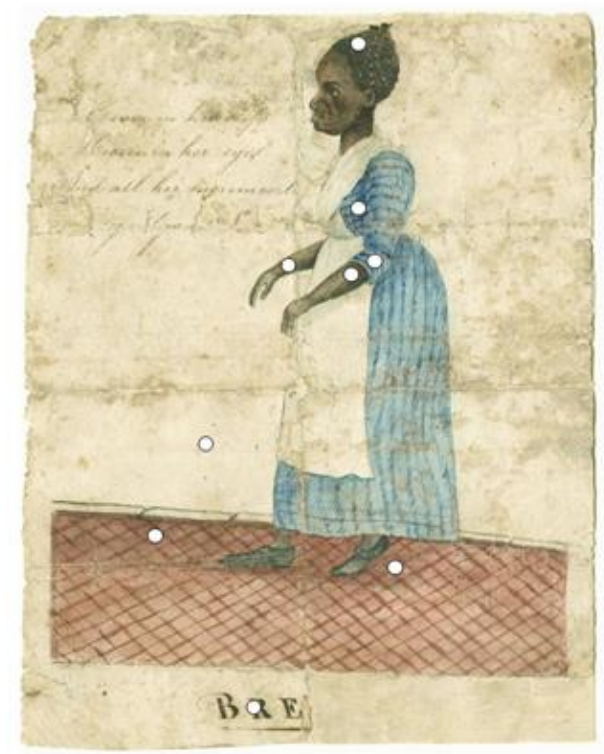

Fig. 1. Selected points for microfadeometry analysis on the $19.1 \mathrm{~cm}$ by $15.6 \mathrm{~cm}$ Miss Breme Jones watercolor.

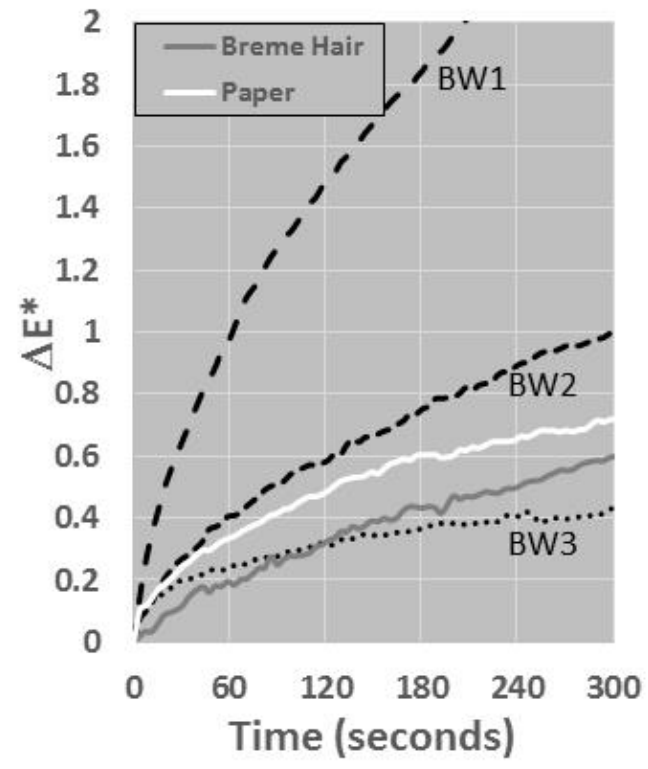

Fig. 3. Change of color in $\Delta E^{*}$ for the analytical area on the hair and paper region as function of time.

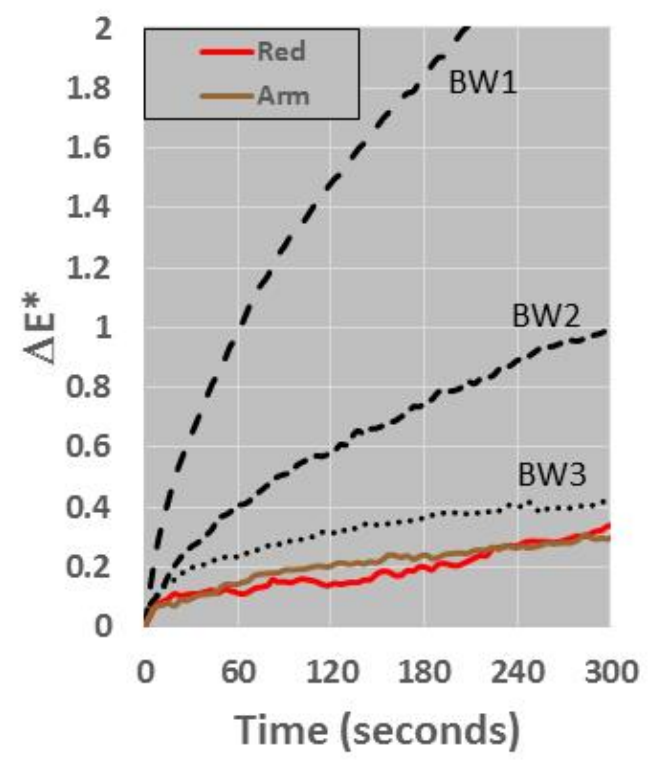

Fig. 2. Change of color in $\Delta E^{*}$ average for the red and average for the arm region as function of time.

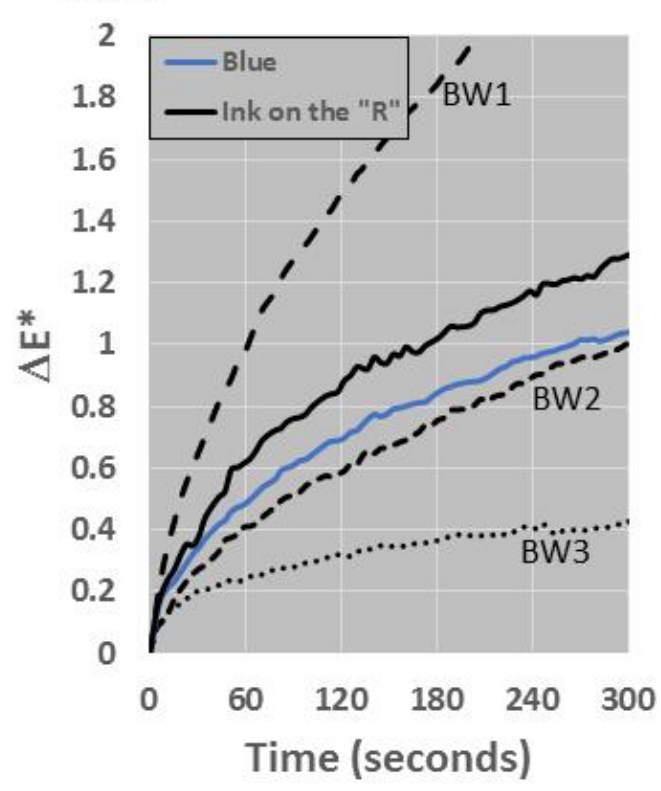

Fig. 4. Change of color in $\Delta E^{*}$ average for the blue region and ink on the "R" as a function of time. 